\title{
Early retinal degeneration in Huntington's disease based on optical coherence tomography: a case- control study
}

\author{
Sergey Svetozarskiy ${ }^{1}$, Svetlana Kopishinskaya ${ }^{2}$ and Igor Smetankin ${ }^{3}$ \\ ${ }^{I}$ Department of Ophthalmology, Volga District Medical Centre under Federal Medical and Biological Agency, Nizhny Novgorod, \\ Russia \\ ${ }^{2}$ Neurology Department of Kirov State Medical University, Kirov, Kirov Oblast, Russia \\ ${ }^{3}$ Ophthalmology Department, Privolzhsky Research Medical University, Nizhny Novgorod, Russia
}

\begin{abstract}
Background: The purpose of this study was to analyze optical coherence tomography (OCT) parameters of the choroid and retina in subjects with pre-manifest and manifest Huntington's disease (HD).

Methods: In this case-control study, the retinal parameters of patients with genetically confirmed HD and healthy controls were evaluated using spectral-domain optical coherence tomography (SD-OCT). Genetic and neurological assessments were performed besides a thorough ophthalmological examination. Contrast Sensitivity (CS) logarithm was evaluated using the Freiburg Vision Test. The association between OCT parameters and clinical and genetic characteristics was studied.

Results: A total of 91 subjects, including $60 \mathrm{HD}$ subjects ( 60 eyes) and 31 control subjects ( 31 eyes) were eligible according to the inclusion and exclusion criteria. The range of the CAG (cytosine-adenine-guanine) repeat expansion size was 38-56 repeats, the mean \pm standard deviation (SD) of the Unified HD Rating Scale (UHDRS) motor scores was $36.3 \pm 29.7$, and disease duration was $13.7 \pm 7.2$ years in HD subjects. Compared to the control group, significant decreases in the mean ganglion cell complex thickness and mean, temporal, superior, inferior, and nasal retinal nerve fiber layer (RNFL) thickness in HD subjects was revealed in OCT examination ( $P$-values $<0.001,<0.001,<0.001,0.023,0.007$, and 0.014 , respectively). An inverse correlation between the disease duration and the mean RNFL thickness $(r=-0.470 ; P=0.002)$ was found. Conclusions: Localization of retinal thickness loss shows a specific pattern of retinal neurodegeneration in HD, similar to Parkinson's disease and mitochondrial diseases. The association with the disease duration confirms the progressive nature of these changes.
\end{abstract}

\section{KEYWORDS}

spectral-domain optical coherence tomography, SD-OCT, Huntington's disease, neurodegenerative diseases, retina

\section{INTRODUCTION}

The ability to use the retina as a "window" to the central nervous system has attracted special attention in recent years [1]. Retinal optical coherence tomography (OCT) parameters are considered potential biomarkers of several neurological diseases, such as multiple sclerosis, neuromyelitis optica, Alzheimer's disease, and Parkinson's

Correspondence: Sergey Svetozarskiy, Ophthalmologist, Ophthalmology Department of Volga District Medical Center of Federal Medical and Biological Agency of Russia, E-mail: svetozarskij@rambler.ru ORCID iD: https://orcid.org/0000-0002-7472-4883

How to cite this article: Svetozarskiy S, Kopishinskaya S, Smetankin I. Early retinal degeneration in Huntington's disease based on optical coherence tomography findings: a case-control study. Med Hypothesis Discov Innov Optom. 2020 Summer; 1(1): 18-24. DOI: https://doi.org/10.51329/ mehdioptometry103

Received: 01 August 2020; Accepted: 28 August 2020

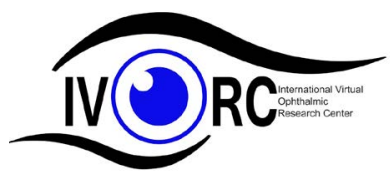

Copyright (C) Author(s). This is an open-access article distributed under the terms of the Creative Commons Attribution-NonCommercial 4.0 International License (http://creativecommons.org/licenses/by-nc/4.0/) which permits copy and redistribute the material just in noncommercial usages, provided the original work is properly cited. (c) (i) $\Theta$ 
disease (PD) [2-4]. In a recent longitudinal study, the sensitivity of the prognostic value of retinal OCT in the discrimination of preclinical stages of Alzheimer's disease was 87\% [5].

Huntington's disease (HD) is a steadily progressing, fully penetrant neurodegenerative disease caused by a dominantly inherited cytosine-adenine-guanine (CAG) trinucleotide repeat expansion in the huntingtin gene [6].

The prevalence of the disease in the Caucasian race is 4.64-13.7 per 100/000 [7-10]. The pre-manifest and manifest stages can be distinguished in the development of the disease [11-13], and the age at the time of motor clinical onset correlates with the number of CAG repeats $[13,14]$. The monogenic nature of inheritance, high penetrance, and the exceptional possibility of monitoring patients at the asymptomatic stage of the disease let us to consider HD as an exceptional «model» disease for studying the early stages of sporadic neurodegenerative diseases [15] for a thorough investigation of the retina and the choroid in pre-manifest and manifest HD [15]. The first study on retinal OCT in HD was announced in 2014 [16], showing peripapillary retinal nerve fiber layer (RNFL) degeneration. Kersten et al. [17], Andrade et al. [18], Sevim et al. [19], Gatto et al. [20], and Tsokolas et al. [21] presented a comprehensive analysis of retinal OCT parameters in groups of 8, 26, 15, 14, and $16 \mathrm{HD}$ patients, respectively. Kersten et al. established peripapillary RNFL thinning in the temporal quadrant [17], Gatto et al. observed temporal and superior thinning RNFL [20], and Gulmes et al. showed thinning of the inner retinal layer in HD [19]. However, Andrade et al. found no changes in RNFL thickness; they observed only macular choroidal thickness loss [18], which was confirmed by Tsokolas [21].

The small group volume and insufficient data on pre-manifest HD require further research. We aimed to analyze OCT parameters of choroid and retina in subjects with pre-manifest and manifest HD, and compare them to the control group.

\section{METHODS}

A case-control study was performed between January 2016 and December 2019. All HD subjects were genetically confirmed. Healthy volunteers were recruited from the control group. The study was approved by the Institutional Ethical Committee of Privolzhsky Research Medical University, Nizhny Novgorod, Russian Federation. The study adhered to the principles of the Declaration of Helsinki. All participants provided informed consent before participating in the study.

Genetic and neurological assessments were performed as follows: CAG repeat length in the huntingtin gene was evaluated in the HD group (by the Center for Molecular Genetics, Moscow, Russia). A neurological examination was performed by a specialist at the Neurology Department of Privolzhsky Research Medical University, Nizhny Novgorod, Russian Federation. Disease duration, Unified Huntington's Disease Rating Scale (UHDRS) motor scores, and disease stage was determined. The control subjects' assessment included a family history taking and neurological examination, together with an evaluation of cognitive function using the MiniMental State Examination (MMSE) scale [5].

A thorough ophthalmological examination was performed at the Ophthalmology Department of the Volga District Medical Center of the Federal Medical and Biological Agency of Russia. Complete medical history was recorded. Best-corrected visual acuity (BCVA), intraocular pressure (IOP) measurement with Goldmann tonometry, biomicroscopy, and indirect ophthalmoscopy with aspherical lenses after pupil dilation were performed in all groups. Contrast Sensitivity (CS) logarithm was evaluated using the Freiburg Vision Test ('FrACT', Version 3.8.1) from a $200 \mathrm{~cm}$ distance [22]. Spectral-domain optical coherence tomography (RTVue-100 spectral-domain OCT; Optovue Inc., Fremont, CA, USA) was used. All scans were performed during the day (from 12 to $2 \mathrm{p} . \mathrm{m}$ ). The choroid thickness in the central fovea was measured manually on the vertical and horizontal retinal scans obtained with the cross-line mode and then the mean value was calculated. The peripapillary RNFL thickness within a diameter of 3.46 millimeters $(\mathrm{mm})$ was assessed using the optic nerve head $(\mathrm{ONH})$ and 3-dimensional optic disk assessment (3D Disc) (RNFL Thickness Analysis) protocols. The mean thickness of the four quadrants was analyzed. The ganglion cell complex (GCC) includes; the RNFL, ganglion cell layer, and inner plexiform layer. The mean GCC thickness was evaluated using the GCC protocol. As the GCC protocol provides no quantitative information concerning GCC thickness in parafovea and perifovea, we attempted to classify these changes effectively using the significance map. We differentiated parafoveal GCC loss, perifoveal arcuate thinning, and nonspecific changes. Scans obtained with a signal strength index (SSI) of less than 50 or in the presence of artifacts (saccades, incorrect focusing of the device at the center of the optic nerve head, etc.) were excluded from the study. Ophthalmological and OCT examinations were performed by an ophthalmologist.

Ophthalmic exclusion criteria were; BCVA below 0.9 (decimal), spherical or astigmatic refractive errors above 
3 diopters, IOP greater than $21 \mathrm{~mm}$ of mercury $(\mathrm{mmHg})$ or the difference between the eyes more than $2 \mathrm{mmHg}$, the vertical cup to disc ratio of more than 0.4 (according to the OCT), any significant optical media opacity, previous ocular trauma or surgery (including laser), any coexisting ocular diseases, and the use of eye drops (except for lubricants).

Neurological and other exclusion criteria for the control group were an MMSE score of less than 26, positive family history in terms of neurodegenerative diseases and any significant neurological abnormality found during the neurological examination, age below 18 or older than 59 years, previous head trauma, diabetes, arterial hypertension, ischemic heart disease, and other systemic diseases with potential damage to the eyes and chronic alcohol or hormonal use. Participants were advised to avoid any physical activity and caffeine-containing drinks two hours before the examination. Those with a systolic blood pressure beyond $125 \mathrm{mmHg}$ or diastolic blood pressure beyond $85 \mathrm{mmHg}$ at the beginning of the survey were also excluded.

Data were analyzed using the IBM Statistical Package for Social Sciences (SPSS) Statistics for Windows, version 22 (IBM Corp., Armonk, N.Y., USA) Continuous variables were presented as arithmetic mean \pm standard deviation (SD). The normality of the data distribution was verified using the Shapiro-Wilk test. Student's $t$-test for independent samples was used for samples with a normal distribution. ANOVA was used as appropriate. Categorical variables (sex) were compared using the chi-square test. The association between OCT parameters and clinical and genetic characteristics was studied using Pearson's correlation. The accepted significance level was set at $5 \%(P<0.05)$. There was a correlation between the right and left eye parameters; therefore, the analysis was performed for the right eye of each subject.

\section{RESULTS}

A total of 91 subjects, including $60 \mathrm{HD}$ subjects (60 eyes) and 31 control subjects (31 eyes) were eligible according to the inclcusion and exclusion criteria. In the HD group, there were 29 pre-manifest and 31 manifest patients. The CAG repeat length varied from 38 to 56 (mean \pm SD; $44.3 \pm 3.8$ ), the mean \pm SD of UHDRS motor scores in the manifest patients was $36.3 \pm 29.7$, and the mean \pm SD of disease duration was $13.7 \pm 7.2$ years. Differences in age, sex, BCVA, and IOP between the case and control groups were not significant $(P=$ $0.90,0.599,0.26$, and 0.945 , respectively) (Table 1 ).The manifest patients were older than the pre-manifested subjects $(P<0.001)$, which is explained by the sequential development of the stages of the disease. The CS logarithm was significantly lower in both pre-manifest $(P=0.002)$ and manifest $(P<0.001)$ HD subjects compared to the controls.

The pre-manifest HD subjects showed a significantly lower thickness of the subfoveal choroid $(P=0.006)$, mean GCC $(P<0.001)$, mean RNFL thickness $(P=0.002)$, and temporal RNFL thickness $(P<0.001)$ compared to the controls. In addition to having significantly lower values for these parameters $(P<0.001)$, the manifest HD patients also had lower nasal $(P=0.033)$ and inferior RNFL thickness $(P=0.010)$ compared to controls (Table 2). GCC scans could be unambiguously classified as parafoveal GCC loss in 16 HD patients, including 13 manifest and 3 pre-manifest subjects (Figure 1). There were no scans with signs of perifoveal arcuate thinning. Subfoveal choroidal thickness was negatively correlated with disease duration $(\mathrm{r}=-0.62 ; P<0.001)$. The mean GCC thickness $(\mathrm{r}=-0.66 ; P=0.003)$ and temporal RNFL thickness $(\mathrm{r}=-0.59 ; P=0.010)$ were negatively correlated with the UHDRS motor score. A significant but mild association $(\mathrm{r}<0.50 ; P<0.05)$ was found between structural parameters, including subfoveal choroidal thickness, mean GCC, and mean RNFL thickness with CAG repeat length, as well as, between mean GCC, and mean RNFL thickness with disease duration (Table 3). However, there was no significant correlation between CS logarithm and OCT parameters.

Table 1. Baseline characteristics of the study participants

\begin{tabular}{|l|l|l|l|l|l|}
\hline Parameter & $\begin{array}{l}\text { All HD subjects } \\
(\mathbf{n}=\mathbf{6 0}) \\
\text { Mean } \pm \text { SD }\end{array}$ & $\begin{array}{l}\text { Pre-manifest HD } \\
(\mathbf{n = 2 9 )} \\
\text { Mean } \pm \text { SD }\end{array}$ & $\begin{array}{l}\text { Manifest HD } \\
(\mathbf{n = 3 1 )} \\
\text { Mean } \pm \text { SD }\end{array}$ & $\begin{array}{l}\text { Controls }(\mathbf{n}=31) \\
\text { Mean } \pm \text { SD }\end{array}$ & $\begin{array}{l}\text { P-value* } \\
\text { HD versus } \\
\text { controls }\end{array}$ \\
\hline Age (y) & $37.6 \pm 10.2$ & $30.63 \pm 4.62$ & $42.60 \pm 10.20$ & $37.3 \pm 10.8$ & 0.90 \\
\hline BCVA (decimal) & $1.0 \pm 0.0$ & $1.0 \pm 0.0$ & $1.0 \pm 0.0$ & $1.0 \pm 0.1$ & 0.26 \\
\hline CS $(\mathbf{L o g})$ & $1.712 \pm 0.210$ & $1.785 \pm 0.166$ & $1.646 \pm 0.227$ & $2.005 \pm 0.141$ & $<\mathbf{0 . 0 0 1}$ \\
\hline IOP $(\mathbf{m m H g})$ & $19.3 \pm 1.7$ & $18.9 \pm 1.4$ & $19.5 \pm 1.8$ & $19.3 \pm 1.5$ & 0.945 \\
\hline
\end{tabular}

Abbreviations: HD, Huntington's disease; n, number; SD, standard deviation; y, years; log CS, contrast sensitivity logarithm; BCVA, best-corrected visual acuity; IOP, intraocular pressure; mmHg, millimeter of mercury. ${ }^{*} t$-test significance. $P<0.05$ is shown in bold. 
Table 2. Retinal and choroidal thickness parameters in the study participants

\begin{tabular}{|c|c|c|c|c|c|c|}
\hline Parameter $(\boldsymbol{\mu m})$ & $\begin{array}{l}\text { Pre-manifest } \\
\text { HD }(n=29) \\
\text { Mean } \pm \text { SD }\end{array}$ & $\begin{array}{l}\text { Manifest HD } \\
(\mathbf{n}=31) \\
\text { Mean } \pm \text { SD }\end{array}$ & $\begin{array}{l}\text { Controls }(\mathbf{n}=31) \\
\text { Mean } \pm \text { SD }\end{array}$ & $\begin{array}{l}P \text {-value } \\
\text { All HD versus } \\
\text { CS }\end{array}$ & $\begin{array}{l}P \text {-value Pre- } \\
\text { Manifest HD } \\
\text { versus CS }\end{array}$ & $\begin{array}{l}P \text {-value } \\
\text { Manifest HD } \\
\text { versus CS }\end{array}$ \\
\hline Subfoveal choroid & $262.6 \pm 50.5$ & $239.7 \pm 25.5$ & $315.1 \pm 74.1$ & $<0.001$ & 0.006 & $<0.001$ \\
\hline Mean GCC & $85.36 \pm 6.43$ & $84.70 \pm 8.66$ & $93.8 \pm 5.2$ & $<0.001$ & $<0.001$ & $<0.001$ \\
\hline Mean RNFLT & $99.86 \pm 8.74$ & $93.74 \pm 8.96$ & $105.7 \pm 7.5$ & $<0.001$ & 0.002 & $<0.001$ \\
\hline Temporal RNFLT & $69.29 \pm 12.41$ & $69.44 \pm 16.67$ & $86.8 \pm 6.9$ & $<0.001$ & $<0.001$ & $<0.001$ \\
\hline Superior RNFLT & $122.14 \pm 12.50$ & $109.86 \pm 15.31$ & $119.5 \pm 14.4$ & 0.023 & 1.0 & 0.076 \\
\hline Nasal RNFLT & $76.43 \pm 7.62$ & $71.86 \pm 11.65$ & $80.5 \pm 12.9$ & 0.014 & 0.051 & 0.033 \\
\hline Inferior RNFLT & $133.64 \pm 15.39$ & $125.32 \pm 14.74$ & $138.7 \pm 18.0$ & 0.007 & 0.075 & 0.010 \\
\hline
\end{tabular}

Abbreviations: $\mu \mathrm{m}$, micrometer; $\mathrm{n}$, number; SD, standard deviation; HD, Huntington's disease; CS, control subjects; GCC, ganglion cell complex; RNFLT, retinal nerve fiber layer thickness. $P<0.05$ is shown in bold."ANOVA.

Table 3. Correlation Between Structural Parameters and Markers of Disease Progression in Patients With HD

\begin{tabular}{|l|l|l|l|l|l|l|l|l|l|}
\hline Parameter $(\boldsymbol{\mu m})$ & \multicolumn{2}{|c|}{ CAG repeat length } & \multicolumn{2}{l|}{ Disease duration $(\mathbf{y})$} & \multicolumn{1}{l|}{ UHDRS Motor Score } & Log CS \\
\hline & $\mathbf{r}$ & $\boldsymbol{P}$-value & $\mathbf{r}$ & $\boldsymbol{P}$-value & $\mathbf{r}$ & $\boldsymbol{P}$-value & $\mathbf{r}$ & $\boldsymbol{P}$-value \\
\hline Subfoveal choroid thickness & -0.342 & $\mathbf{0 . 0 3 1}$ & -0.619 & $<\mathbf{0 . 0 0 1}$ & -0.041 & 0.871 & -0.078 & 0.758 \\
\hline Mean GCC & -0.487 & $\mathbf{0 . 0 0 1}$ & -0.440 & $\mathbf{0 . 0 0 3}$ & -0.657 & $\mathbf{0 . 0 0 3}$ & -0.199 & 0.201 \\
\hline Mean RNFLT & -0.389 & $\mathbf{0 . 0 1 4}$ & -0.470 & $\mathbf{0 . 0 0 2}$ & -0.433 & 0.082 & -0.093 & 0.558 \\
\hline Temporal RNFLT & -0.134 & 0.409 & -0.110 & 0.483 & -0.590 & $\mathbf{0 . 0 1 0}$ & 0.238 & 0.124 \\
\hline
\end{tabular}

Abbreviations: HD, Huntington's disease; $\mu \mathrm{m}$, micrometer; y, years; GCC, ganglion cell complex; RNFLT, retinal nerve fiber layer thickness; log CS, contrast sensitivity logarithm; UHDRS, Unified Huntington's Disease Rating Scale; CAG, cytosine-adenineguanine. $P<0.05$ is shown in bold.

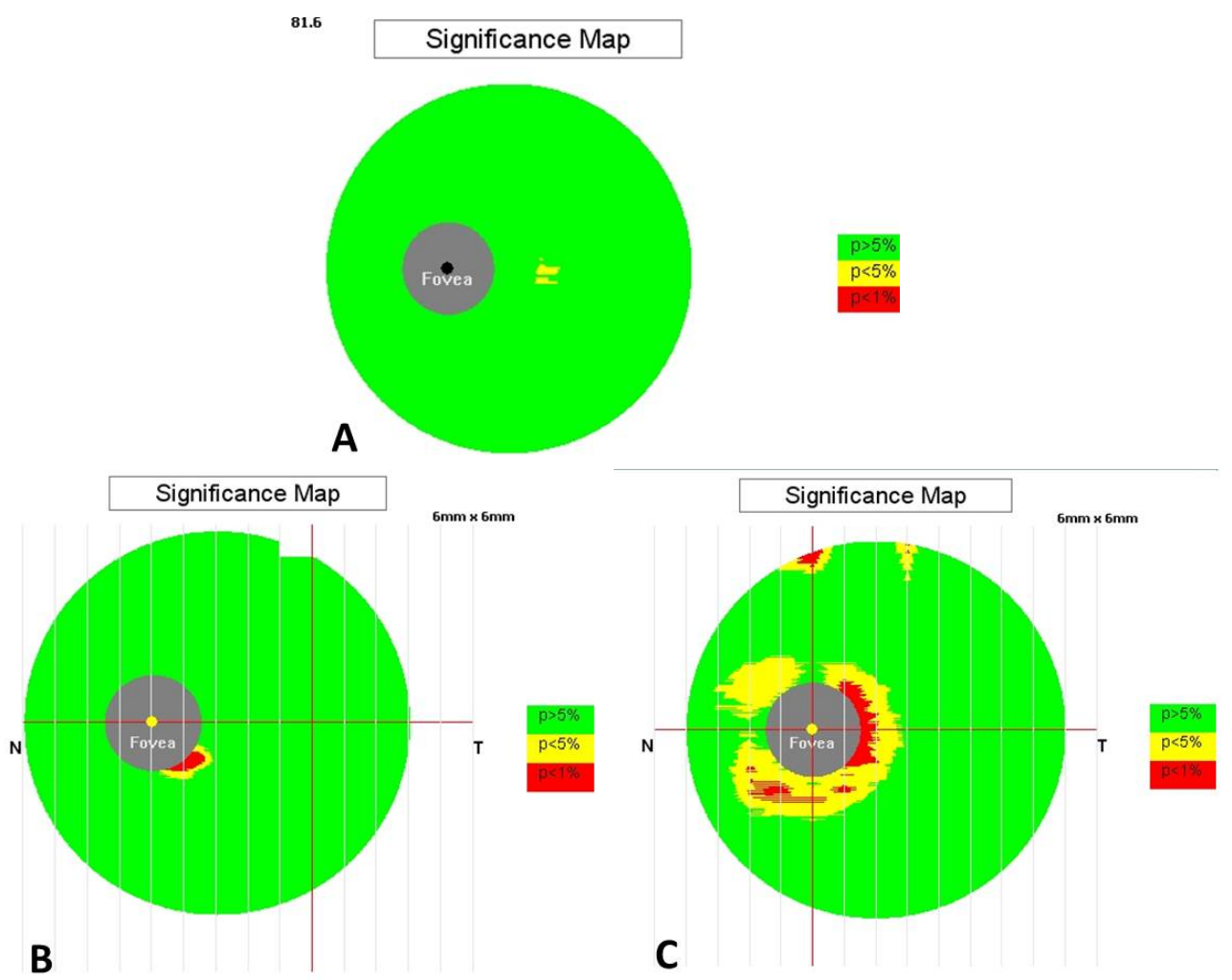

Figure 1. Sample Ganglion cell complex (GCC) significance maps of the subjects; (A). The left eye of the control subject, 25 years old, having no abnormalities; (B). The left eye of the pre-manifest Huntington's disease (HD) subject, 25 years old, showing slight parafoveal degeneration; (C). The left eye of the manifest HD subject, 41 years old, having marked parafoveal ganglion cell loss. 


\section{DISCUSSION}

The main finding of this study was a specific parvocellular pattern of retinal neurodegeneration characterized by parafoveal GCC thinning and predominantly temporal RNFL loss in both pre-manifest and manifest HD subjects (Figure 1). Less pronounced but significant RNFL thickness reduction in the nasal and inferior quadrants was described in the manifest HD patients for the first time. GCC degeneration and temporal RNFL thinning were associated with increased UHDRS motor scores. Macular choroid atrophy correlated with disease duration, and CAG repeat length showed a mild inverse association with some OCT parameters. Nevertheless, previous studies have shown that CS loss [23] did not have any correlation with OCT parameters.

The study of retinal structures in neurodegenerative diseases has been performed by various teams since 2004 [24]. There has been a growing interest to study the choroid structure in the last few years because it consists of the end branches of the internal carotid artery that feeds the structures of the brain. A thinning macular choroid has been described in Alzheimer's disease [25] and PD [26], while peripapillary choroid was thickened in PD [21]. The choroid macular thinning in HD was detected by Andrade et al. for the first time while the peripapillary choroid did not show any significant changes [18]. Tsokolas et al. reported thining of temporal and superior RNFL in HD patients against healthy controls and outlined a reduced macular thickness [21]. We aimed to prove these findings in a larger and more heterogeneous clinical sample. Our results are very similar to those of Andrade et al. [18]. The choroid is a dynamic structure, its thickness is determined both by functional state and structural remodeling $[27,28]$. Thinning of the macular choroid in HD can be considered a consequence of intracranial hemodynamic disturbances, probably associated with abnormal huntingtin accumulation in the cerebral vessels [29].

Ganglion cells are third-order neurons of the visual analyzer; their axons go in the RNFL and compose the optic nerve. Thinning of GCC and RNFL have been described in Alzheimer's [3, 30] and PD [31]. According to a meta-analysis of 887 patients with Alzheimer's disease, the most pronounced RNFL reduction was detected in the upper and lower quadrants related to the magnocellular system [32]. A similar pattern of retinal degeneration has been noted in glaucoma [33,34], and similarities in the pathogenesis of Alzheimer's disease and glaucoma have been previously reported $[35,36]$. The results of RNFL assessment in PD indicate a preferential temporal RNFL reduction $[24,26,31,35]$, which is more consistent with optic nerve atrophy in mitochondrial diseases, such as Leber's hereditary optic neuropathy [37]. According to the similarity of the pathogenesis of PD and HD, La Morgia et al. suggested that the development of optic neuropathy in HD should have a parvocellular pattern compared to Alzheimer's disease and glaucoma [38]. However, previous visual functional studies have revealed different findings in patients with HD. O'Donnell et al. assumed a major lesion of the magnocellular pathway [39], while a recent study [23] showed early dysfunction of the parvocellular pathway, which is consistent with the results of the current study.

Our data support the hypothesis of La Morgia et al. [38] according to parafoveal GCC degeneration with the most pronounced temporal RNFL loss in both pre -and manifest HD subjects, this is in accordance with the results of Kersten et al. and Gatto et al. $[17,20]$. This phenomenon could be explained by mitochondrial dysfunction in $\mathrm{HD}[17,40]$, causing the death of the most energy-consuming cells, in particular, ganglion cells [41], which is consistent with experimental data suggesting an earlier lesion of cones than rods in the course of HD progression [42]. At the same time, less pronounced but significant RNFL thinning in the nasal and inferior quadrants tends to progress at the manifest stage, indicating that retinal neurodegeneration is not restricted to the parvocellular pathway only but involves the magnocellular pathway as well in the manifest stage.

This study had some limitations. The major one was its cross-sectional design, with no data on the retinal degeneration progression rate. Subjective manual choroid thickness assessment suggests a higher risk of bias than computer analysis in more recent OCT devices [43]. In addition, axial eye length was not considered, but the refraction was considered [44]. Nevertheless, our data on choroid thickness were consistent with some previous results [18], obtained using a standard protocol. The visual function assessment consisted of visual acuity and CS tests that showed no significant correlation with OCT data; therefore, further research is required.

However, the current study also has some strengths. There were 60 genetically confirmed clinically heterogeneous $\mathrm{HD}$ subjects who were compared with the healthy control group. The main factors affecting OCT results included patients' health issues, functional states, and image artifacts [45-47]. As a result, we attempted to add new findings to an extremely insufficient understanding of visual dysfunction in $\mathrm{HD}$ [48]. The association between OCT parameters and visual functions, including quantitative examination of color sensitivity in HD and the course of retinal degeneration as part of a prospective study, requires further research. It is also critical to identify the link between retinal dysfunction and mitochondrial biogenesis in HD. 


\section{CONCLUSIONS}

An interdisciplinary approach used in the diagnosis and monitoring of neurodegenerative diseases using new noninvasive biomarkers is necessary. Our results confirmed that macular choroidatrophy, ganglion cells, and axon degeneration start early in the course of the disease. Ganglion cells and RNFL thinning have a specific pattern of preferential parvocellular degeneration, which is probably associated with mitochondrial dysfunction. Clinical deterioration at the manifest stage of $\mathrm{HD}$ is accompanied by progressive retinal and choroid degeneration, yet, CAG repeat length has a mild correlation with some OCT parameters.

\section{ETHICS DECLARATION}

Ethical approval: This study was approved by the Institutional Local Ethical Committee of Privolzhsky Research Medical University, Russia.

Conflict of interest: The authors declare no conflicts of interest.

\section{FUNDING}

\section{None.}

\section{ACKNOWLED GMENT}

\section{None.}

\section{REFERENCES}

1. Doustar J, Torbati T, Black KL, Koronyo Y, Koronyo-Hamaoui M. Optical Coherence Tomography in Alzheimer's Disease and Other Neurodegenerative Diseases. Front Neurol. 2017;8:701. doi:10.3389/fneur.2017.00701 pmid:29312125

2. Svetozarskiy SN, Kopishinskaya SV. Retinal Optical Coherence Tomography in Neurodegenerative Diseases (Review). Sovremennye tehnologii v medicine. 2015;7(1):116-23. doi:10.17691/stm2015.7.1.14

3. Sadda SR, Borrelli E, Fan W, Ebraheem A, Marion KM, Harrington M, et al. A pilot study of fluorescence lifetime imaging ophthalmoscopy in preclinical Alzheimer's disease. Eye (Lond). 2019;33(8):1271-9. doi:10.1038/s41433-019-0406-2 pmid:30923356

4. Ngolab J, Honma P, Rissman RA. Reflections on the Utility of the Retina as a Biomarker for Alzheimer's Disease: A Literature Review. Neurol Ther. 2019;8(Suppl 2):57-72. doi:10.1007/s40120-019-00173-4 pmid:31833024

5. Asanad S, Fantini M, Sultan W, Nassisi M, Felix CM, Wu J, et al. Retinal nerve fiber layer thickness predicts CSF amyloid/tau before cognitive decline. PLoS One. 2020;15(5):e0232785. doi:10.1371/journal.pone.0232785 pmid:32469871

6. McColgan P, Tabrizi SJ. Huntington's disease: a clinical review. Eur J Neurol. 2018;25(1):24-34. doi:10.1111/ene.13413 pmid:28817209

7. Morrison PJ, Harding-Lester S, Bradley A. Uptake of Huntington disease predictive testing in a complete population. Clin Genet. 2011;80(3):281-6. doi:10.1111/j.1399-0004.2010.01538.x pmid:20880124

8. Demetriou CA, Heraclides A, Salafori C, Tanteles GA, Christodoulou K, Christou Y, et al. Epidemiology of Huntington disease in Cyprus: A 20-year retrospective study. Clin Genet. 2018;93(3):656-64. doi:10.1111/cge.13168 pmid:29105741

9. Fisher ER, Hayden MR. Multisource ascertainment of Huntington disease in Canada: prevalence and population at risk. Mov Disord. 2014;29(1):105-14. doi:10.1002/mds.25717 pmid:24151181

10. Evans SJ, Douglas I, Rawlins MD, Wexler NS, Tabrizi SJ, Smeeth L. Prevalence of adult Huntington's disease in the UK based on diagnoses recorded in general practice records. J Neurol Neurosurg Psychiatry. 2013;84(10):1156-60. doi:10.1136/jnnp-2012304636 pmid:23482661

11. Ghosh R, Tabrizi SJ. Clinical Features of Huntington's Disease. Adv Exp Med Biol. 2018;1049:1-28. doi:10.1007/978-3-319-717791_1 pmid:29427096

12. Reilmann R, Leavitt BR, Ross CA. Diagnostic criteria for Huntington's disease based on natural history. Mov Disord. 2014;29(11):1335-41. doi:10.1002/mds.26011 pmid:25164527

13. Bates GP, Dorsey R, Gusella JF, Hayden MR, Kay C, Leavitt BR, et al. Huntington disease. Nat Rev Dis Primers. $2015 ; 1: 15005$. doi: $10.1038 /$ nrdp.2015.5 pmid:27188817

14. Ross CA, Aylward EH, Wild EJ, Langbehn DR, Long JD, Warner JH, et al. Huntington disease: natural history, biomarkers and prospects for therapeutics. Nat Rev Neurol. 2014;10(4):204-16. doi:10.1038/nrneurol.2014.24 pmid:24614516

15. Kloppel S, Gregory S, Scheller E, Minkova L, Razi A, Durr A, et al. Compensation in Preclinical Huntington's Disease: Evidence From the Track-On HD Study. EBioMedicine. 2015;2(10):1420-9. doi:10.1016/j.ebiom.2015.08.002 pmid:26629536

16. Kopishinskaya S, Svetozarskiy S, Antonova V, Gustov A. The first data on retinal optical coherence tomography parameters in Huntington's disease. Eur J Neurol 2014;21(36). Link

17. Kersten HM, Danesh-Meyer HV, Kilfoyle DH, Roxburgh RH. Optical coherence tomography findings in Huntington's disease: a potential biomarker of disease progression. J Neurol. 2015;262(11):2457-65. doi:10.1007/s00415-015-7869-2 pmid:26233693

18. Andrade C, Beato J, Monteiro A, Costa A, Penas S, Guimaraes J, et al. Spectral-Domain Optical Coherence Tomography as a Potential Biomarker in Huntington's Disease. Mov Disord. 2016;31(3):377-83. doi:10.1002/mds.26486 pmid:26853218

19. Gulmez Sevim D, Unlu M, Gultekin M, Karaca C. Retinal single-layer analysis with optical coherence tomography shows inner retinal layer thinning in Huntington's disease as a potential biomarker. Int Ophthalmol. 2019;39(3):611-21. doi:10.1007/s10792-018-08577 pmid:29435796 
20. Gatto E, Parisi V, Persi G, Fernandez Rey E, Cesarini M, Luis Etcheverry J, et al. Optical coherence tomography (OCT) study in Argentinean Huntington's disease patients. Int J Neurosci. 2018;128(12):1157-62. doi:10.1080/00207454.2018.1489807 pmid:29912591

21. Tsokolas G, Tsaousis KT, Diakonis VF, Matsou A, Tyradellis S. Optical Coherence Tomography Angiography in Neurodegenerative Diseases: A Review. Eye Brain. 2020;12:73-87. doi: 10.2147/EB.S193026 pmid: 32765149

22. Bach M. The Freiburg Visual Acuity Test-variability unchanged by post-hoc re-analysis. Graefes Arch Clin Exp Ophthalmol. 2006;245(7):965-71. doi:10.1007/s00417-006-0474-4 pmid:17219125

23. Svetozarskiy SN. Contrast Sensitivity and Color Vision as Biomarkers of the Preclinical Stage of Neurodegeneration in Huntington's Disease. Sovremennye tehnologii v medicine. 2019;11(2):77-85. doi:10.17691/stm2019.11.2.11

24. Inzelberg R, Ramirez JA, Nisipeanu P, Ophir A. Retinal nerve fiber layer thinning in Parkinson disease. Vision Res. 2004;44(24):27937. doi:10.1016/j.visres.2004.06.009 pmid:15342223

25. Cunha JP, Proenca R, Dias-Santos A, Melancia D, Almeida R, Aguas H, et al. Choroidal thinning: Alzheimer's disease and aging Alzheimers Dement (Amst). 2017;8:11-7. doi:10.1016/j.dadm.2017.03.004 pmid:28435851

26. Eraslan M, Cerman E, Yildiz Balci S, Celiker H, Sahin O, Temel A, et al. The choroid and lamina cribrosa is affected in patients with Parkinson's disease: enhanced depth imaging optical coherence tomography study. Acta Ophthalmol. 2016;94(1):e68-75. doi: $10.1111 /$ aos. 12809 pmid:26268377

27. Garcia-Martin E, Pablo LE, Bambo MP, Alarcia R, Polo V, Larrosa JM, et al. Comparison of peripapillary choroidal thickness between healthy subjects and patients with Parkinson's disease. PLoS One. 2017;12(5):e0177163. doi:10.1371/journal.pone.0177163 pmid:28510576

28. Laviers H, Zambarakji H. Enhanced depth imaging-OCT of the choroid: a review of the current literature. Graefes Arch Clin Exp Ophthalmol. 2014;252(12):1871-83. doi:10.1007/s00417-014-2840-y pmid:25363655

29. Drouin-Ouellet J, Sawiak SJ, Cisbani G, Lagace M, Kuan WL, Saint-Pierre M, et al. Cerebrovascular and blood-brain barrier impairments in Huntington's disease: Potential implications for its pathophysiology. Ann Neurol. 2015;78(2):160-77. doi:10.1002/ ana.24406 pmid:25866151

30. Garcia-Martin E, Bambo MP, Marques ML, Satue M, Otin S, Larrosa JM, et al. Ganglion cell layer measurements correlate with disease severity in patients with Alzheimer's disease. Acta Ophthalmol. 2016;94(6):e454-9. doi:10.1111/aos.12977 pmid:26895692

31. Gulmez Sevim D, Unlu M, Gultekin M, Karaca C, Mirza M, Mirza GE. Evaluation of Retinal Changes in Progressive Supranuclear Palsy and Parkinson Disease. J Neuroophthalmol. 2018;38(2):151-5. doi:10.1097/WNO.0000000000000591 pmid:29240574

32. den Haan J, Verbraak FD, Visser PJ, Bouwman FH. Retinal thickness in Alzheimer's disease: A systematic review and meta-analysis. Alzheimers Dement (Amst). 2017;6:162-70. doi:10.1016/j.dadm.2016.12.014 pmid:28275698

33. Eraslan M, Cerman E, Cekic O, Balci S, Dericioglu V, Sahin O, et al. Neurodegeneration in ocular and central nervous systems: optical coherence tomography study in normal-tension glaucoma and Alzheimer disease. Turk J Med Sci. 2015;45(5):1106-14. doi:10.3906/ sag-1406-145 pmid:26738355

34. Cesareo M, Martucci A, Ciuffoletti E, Mancino R, Cerulli A, Sorge RP, et al. Association Between Alzheimer's Disease and Glaucoma: A Study Based on Heidelberg Retinal Tomography and Frequency Doubling Technology Perimetry. Front Neurosci. 2015;9:479. doi: 10.3389/fnins.2015.00479 pmid:26733792

35. Lin IC, Wang YH, Wang TJ, Wang IJ, Shen YD, Chi NF, et al. Glaucoma, Alzheimer's disease, and Parkinson's disease: an 8-year population-based follow-up study. PLoS One. 2014;9(9):e108938. doi:10.1371/journal.pone.0108938 pmid:25275530

36. Davis BM, Crawley L, Pahlitzsch M, Javaid F, Cordeiro MF. Glaucoma: the retina and beyond. Acta Neuropathol. 2016;132(6):80726. doi:10.1007/s00401-016-1609-2 pmid:27544758

37. Majander A, Robson AG, Joao C, Holder GE, Chinnery PF, Moore AT, et al. The pattern of retinal ganglion cell dysfunction in Leber hereditary optic neuropathy. Mitochondrion. 2017;36:138-49. doi:10.1016/j.mito.2017.07.006 pmid:28729193

38. La Morgia C, Di Vito L, Carelli V, Carbonelli M. Patterns of Retinal Ganglion Cell Damage in Neurodegenerative Disorders: Parvocellular vs Magnocellular Degeneration in Optical Coherence Tomography Studies. Front Neurol. 2017;8:710. doi:10.3389/ fneur.2017.00710 pmid:29312131

39. O'Donnell BF, Blekher TM, Weaver M, White KM, Marshall J, Beristain X, et al. Visual perception in prediagnostic and early stage Huntington's disease. J Int Neuropsychol Soc. 2008;14(3):446-53. doi:10.1017/S1355617708080405 pmid:18419843

40. Shirendeb U, Reddy AP, Manczak M, Calkins MJ, Mao P, Tagle DA, et al. Abnormal mitochondrial dynamics, mitochondrial loss and mutant huntingtin oligomers in Huntington's disease: implications for selective neuronal damage. Hum Mol Genet. 2011;20(7):143855. doi: $10.1093 / \mathrm{hmg} / \mathrm{ddr} 024$ pmid:21257639

41. Wong-Riley MT. Energy metabolism of the visual system. Eye Brain. 2010;2:99-116. doi:10.2147/EB.S9078 pmid:23226947

42. Batcha AH, Greferath U, Jobling AI, Vessey KA, Ward MM, Nithianantharajah J, et al. Retinal dysfunction, photoreceptor protein dysregulation and neuronal remodelling in the R6/1 mouse model of Huntington's disease. Neurobiol Dis. 2012;45(3):887-96. doi:10.1016/j.nbd.2011.12.004 pmid:22198376

43. Spaide RF, Koizumi H, Pozzoni MC. Enhanced depth imaging spectral-domain optical coherence tomography. Am J Ophthalmol. 2008;146(4):496-500. doi:10.1016/j.ajo.2008.05.032 pmid:18639219

44. Barteselli G, Chhablani J, El-Emam S, Wang H, Chuang J, Kozak I, et al. Choroidal volume variations with age, axial length, and sex in healthy subjects: a three-dimensional analysis. Ophthalmology. 2012;119(12):2572-8. doi:10.1016/j.ophtha.2012.06.065 pmid:22921388

45. Chakraborty R, Read SA, Collins MJ. Diurnal variations in axial length, choroidal thickness, intraocular pressure, and ocular biometrics. Invest Ophthalmol Vis Sci. 2011;52(8):5121-9. doi:10.1167/iovs.11-7364 pmid:21571673

46. Usui S, Ikuno Y, Akiba M, Maruko I, Sekiryu T, Nishida K, et al. Circadian changes in subfoveal choroidal thickness and the relationship with circulatory factors in healthy subjects. Invest Ophthalmol Vis Sci. 2012;53(4):2300-7. doi:10.1167/iovs.11-8383 pmid:22427554

47. Bazvand F, Ghassemi F. Artifacts in Macular Optical Coherence Tomography. J Curr Ophthalmol. 2020;32(2):123-131. doi: 10.4103/ JOCO.JOCO_83_20 pmid: 32671295

48. Svetozarskiy SN, Kopishinskaya SV, Gustov AV, Radyuk MA, Antonova VA, Smetankin IG, et al. [Ophthalmic manifestations of Huntington's disease]. Vestn Oftalmol. 2015;131(5):82-6. doi:10.17116/oftalma2015131582-86 pmid:26845877 